\title{
A cryptic deletion of $2 q 35$ including part of the PAX3 gene detected by breakpoint mapping in a child with autism and a de novo 2;8 translocation
}

\author{
I Borg, M Squire, C Menzel, K Stout, D Morgan, L Willatt, P C M O'Brien, \\ M A Ferguson-Smith, H H Ropers, N Tommerup, V M Kalscheuer, D R Sargan
}

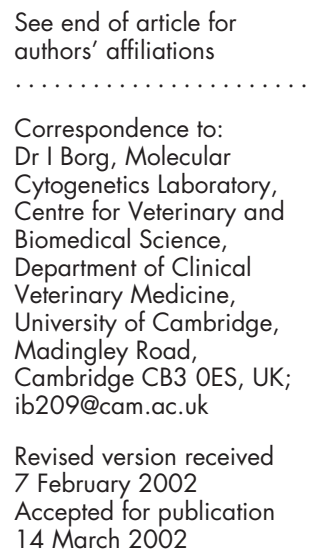

$A^{a}$ utism is a severe neurodevelopmental disorder of childhood. Diagnosis is based on the presence of a combination of abnormal social, communicative, and behavioural functioning presenting before the third year of life and persisting into adulthood. It is a relatively common condition with an incidence of about 5 in 10000 and an average male to female ratio of 3.8:1, the latter varying according to the absence or presence of mental retardation. ${ }^{1}$ A major genetic component for autism has been strongly suggested by twin studies which show a much higher concordance for monozygotic (31-90\%) than dizygotic $(0-3 \%)$ twins. ${ }^{2-4}$

Autism is genetically heterogeneous. Nearly all chromosomes have been implicated in one study or another, with the exclusion of chromosomes 12, 14, 19, and 20. ${ }^{5}$ Genome wide screens by linkage analysis have suggested that loci at $1 \mathrm{p}, 2 \mathrm{q}$, $4 q, 5 p, 6 q, 7 q, 10 q, 15 q, 16 p, 18 q, 19 p, 22 q$, and Xp are implicated in the aetiology of autism. The International Molecular Genetic Study of Autism Consortium (IMGSAC) ${ }^{6}$ and the Paris Autism Research International Sibpair Study (PARISS), ${ }^{8}$ and a recent sib pair based study restricted to cases of autism with phrased speech delay ${ }^{9}$ all identified susceptible regions on chromosome $2 \mathrm{q}$ at around $2 \mathrm{q} 32$. The IMGSAC excluded the entire $\mathrm{X}$ chromosome in stage 2 of their study, ${ }^{6}$ although one marker (DXS996) reached a maximum lod score of 0.5 in the stage 1 data set. On the other hand, the PARISS implicated Xp as a susceptibility region potentially involved in autism. Particular interest has focused on chromosome arms $2 \mathrm{q}, 7 \mathrm{q}$, and 15q. Ghaziuddin and Burmeister ${ }^{10}$ reported four cases (two unpublished) of 2 q37 deletions associated with autism and also reported on other published cases, with deletions ranging from $2 \mathrm{q} 31$ to 2 qter. Conrad $e t$ al ${ }^{11}$ also reported three cases of $2 \mathrm{q} 37$ deletions associated with features that are highly suggestive of autism. Here we have studied an autistic patient with an apparently balanced $(2 ; 8)(\mathrm{q} 35 ; \mathrm{q} 21.2)$ translocation. We have used a battery of molecular cytogenetic and molecular techniques to detect and characterise a cryptic deletion at the translocation breakpoint and to ensure that no other chromosomal abnormalities could be detected.

\section{PATIENT, MATERIALS, AND METHODS}

The proband was ascertained as part of a study of patients with developmental delay and apparently balanced translocations within the Mendelian Cytogenetics Network. ${ }^{12}$ He is the third child of healthy, non-consanguineous, white parents. He is the second twin, born at 32 weeks by caesarean section for fetal distress and intrauterine growth retardation. He was very small for dates, weighing $1130 \mathrm{~g}$, but had few problems in the neonatal period and needed ventilation for under a day, for transient tachypnoea. There was no intracranial haemorrhage. He was a very quiet baby and showed poor socialisation and eye contact from an early age. His parents noted that he was slower than his twin sister from the age of 3 months. At the corrected age of 19 months, he had only just started walking, speech was non-existent, and he was delayed in personal social skills and was difficult to feed. The latter necessitated prolonged hospital admissions, as at times he would completely refuse to drink or eat in spite of there being no physical or mechanical abnormalities. An MRI scan of the brain showed moderately enlarged lateral and third ventricles, but there was no increased intracranial pressure. A diagnosis of arrested hydrocephalus was made and the head circumference continued to grow along the 50th centile. Fundi were reported as normal after examination under anaesthesia. Routine hearing tests at 2 years and 6 years were difficult to carry out owing to the child's lack of cooperation, but were reported as being apparently normal. No auditory evoked potential measurements have been carried out. The proband was reported as being sensitive to high pitched sounds and was more receptive when he was given clear signing as well as verbal explanations and instructions. An assessment by a paediatric neurosurgeon at 4 years ruled out the child's learning difficulties as being the result of the hydrocephalus. A 
metabolic screen, endocrine function, urine amino acids, and routine blood investigations were normal. Chromosome analysis showed a balanced rearrangement between chromosomes 2 and 8, namely, 46,XY,t(2;8)(q36;q21.3). His mother's karyotype was normal, whereas his father was found to have an unrelated balanced rearrangement $46, \mathrm{XY}, \mathrm{t}(5 ; 20)(\mathrm{pl} ; 0 ; \mathrm{pl} 0)$. His twin sister, who carries the paternal translocation, was normal for dates at birth (1900 g) and had made entirely normal progress; his older sister was also developing normally. There was no family history of developmental delay or mental retardation. Based on the persistent abnormal social, communicative, and behavioural functioning, a diagnosis of autism in addition to his learning difficulties was made at the age of 6 years.

When we saw the proband at the age of 11 years, his parents reported significant learning difficulties with behavioural problems still centred on feeding difficulties. He was eating a very small variety of foods and would use his sense of smell in determining preference. He was very particular about routines and showed obsessional behaviour. He was still not toilet trained. He was attending a school for special needs and was using sign language (Makaton) to communicate; he had only started saying some words since the age of 9 . He was unable to maintain eye contact and had a poor concentration span. He did not utter any words. He played repeatedly with his parents' credit cards, flicking them between his hands and occasionally smelling them. He was growing along the 3rd centile for weight, the 10th for height, and along the 50th centile for head circumference. Minor facial dysmorphic features included upward slanting palpebral fissures, mild dystopia canthorum, and prominent antihelices, but he was not dysmorphic overall. The rest of the physical examination was normal. The clinical and developmental history and current function met the DSM-IV diagnostic criteria for autism. An autism diagnostic interview (ADI) was not carried out as the parents declined this. However, it was not felt that the ADI was crucial in confirming the diagnosis, since throughout his development four experienced paediatricians had seen him and independently reached the same diagnosis.

\section{Fluorescence in situ hybridisation}

Standard protocols were used in the preparation of metaphase chromosomes and for fluorescence in situ hybridisation (FISH) studies. Cell line culture preparations from the patient were used to sort the normal and aberrant chromosomes 2 and 8 as well as the $\mathrm{X}$ chromosome, using bivariate flow karyotype analysis. Subtelomeric probes were from the Cytocell Chromoprobe-T kit. Whole chromosome paints were prepared from flow sorted chromosomes using degenerate oligonucleotide primed PCR (DOP-PCR) as described by Telenius et al $^{13}$ and Carter et al. ${ }^{14}$ A 24 colour paint probe was prepared in house from five chromosome pools and the appropriate dUTPs and fluorochromes were again incorporated by DOP-PCR. Cross species colour (RxFISH) paint was also prepared in house. ${ }^{15}$

Breakpoint mapping used CEPH YAC probes selected from the Whitehead Institute contigs, and BACs and PACs from UCSC "Golden Path" (tables 1-3). These were prepared by standard techniques, labelled with appropriately coupled dUTPs by nick translation or directly labelled by DOP-PCR, and used as probes in FISH as before. ${ }^{16}$

\section{Locus specific PCR}

Finer mapping of chromosomal breakpoints and investigation of parental origins of the derivative chromosomes used PCR on sorted chromosome DNA with primers specific for STS markers close to the breakpoints identified by FISH. Normal and derivative chromosomes from the proband were isolated by flow sorting and DNA amplified by DOP-PCR in $100 \mu \mathrm{l}$ reactions as before ${ }^{17}$ and $0.2 \mu \mathrm{l}$ DOP-PCR products were used
Table 1 FISH results using CEPH YAC clones on $2 q$ and $8 q$. Clones bordering or deleted at breakpoint are in bold type.

\begin{tabular}{lllll}
\hline $\begin{array}{l}\text { Genetic } \\
\text { distance }\end{array}$ & STS marker & YAC clone & Size $(\mathrm{kb})$ & FISH result \\
\hline $2 q$ & & & & \\
223 & D2S295 & $817-B-12$ & 950 & Proximal \\
226 & D2S163 & $708-C-9$ & 1600 & Proximal \\
229 & D2S339 & $906-C-3$ & 910 & Proximal \\
$\mathbf{2 2 9}$ & D2S339 & $\mathbf{8 7 9 - H - 9}$ & 1110 & Proximal \\
$\mathbf{2 3 0}$ & D2S2323 & $\mathbf{7 4 3 - C - 9}$ & $\mathbf{1 5 0 0}$ & Deleted \\
$\mathbf{2 3 2}$ & D2S133 & $\mathbf{8 0 2 - A - 9}$ & $\mathbf{1 1 4 0}$ & Deleted \\
$\mathbf{2 3 3}$ & D2S353 & $\mathbf{7 0 3 - E - 9}$ & $\mathbf{1 1 6 0 / 1 6 1 0}$ & Deleted \\
$\mathbf{2 3 3}$ & D2S351 & $\mathbf{8 8 6 - H - 7}$ & $\mathbf{1 7 0 0}$ & Deleted \\
$\mathbf{2 3 4}$ & D2S2204 & $\mathbf{8 7 3 - B - 1 2}$ & $\mathbf{5 1 0}$ & Distal \\
236 & D2S2158 & $933-\mathrm{C}-7$ & 1690 & Distal \\
236 & D2S159 & $929-\mathrm{G}-1$ & 1220 & Distal \\
$\mathbf{8 q}$ & & & & \\
95 & D8S1764 & $790-A-1$ & 1720 & Proximal \\
& D8S1760 & & & \\
97 & D8S275 & $762-B-3$ & 1480 & Proximal \\
101 & D8S271 & $718-D-11$ & 350,540 & Proximal \\
102 & D8S1811 & $820-C-9$ & 1680 & Proximal \\
102 & D8S1724 & $\mathbf{7 5 9 - G - 8}$ & $\mathbf{1 7 3 0}$ & Proximal \\
$\mathbf{1 0 2}$ & D8S270 & $\mathbf{7 2 5 - A - 6}$ & $\mathbf{1 6 2 0}$ & Distal \\
105 & D8S1794 & $751-D-3$ & 1620 & Distal \\
109 & D8S506 & $913-G-5$ & NA & Distal \\
& D8S1778 & & & \\
112 & D8S1808 & $811-A-6$ & 1350 & Distal \\
115 & D8S521 & $662-E-12$ & NA & Distal \\
\hline NA: not available. & & & \\
\hline & & & & \\
\hline
\end{tabular}

as substrates with STS specific primers (as identified in the Uni-STS database) in $20 \mu \mathrm{l}$ reactions. The presence of a particular STS marker in a chromosome was assessed by the ability to amplify it from the DOP-PCR products of the proband's flow sorted normal chromosome and of one or other of the derivative chromosomes. STS primer pairs that failed to amplify the normal chromosome after DOP-PCR were discarded from the analysis. Markers used for Xp were DXYS14, DXYS20, DXYS28, DXYS60, DXYS129, DXYS130, DXYS131, DXYS132, and DXYS153; markers used for the $\operatorname{der}(2)$ and $\operatorname{der}(8)$ chromosomes are tabulated (table 4).

\section{Contigs}

We have used the UCSC Golden Path contigs (Aug 06, 2001 freeze), in compiling figures and tables for this paper, but in STS mapping studies we have also tested STS derived from the NCBI (build 26) and EnsEMBL (Aug 2001 freeze) datasets, where these are different (table 4).

\section{RESULTS}

Karyotype defined by $\mathrm{G}$ banding, chromosome painting, and subtelomeric probes

Re-evaluation of the patient's $\mathrm{G}$ banded karyotype at the 550 band level redefined the breakpoint on chromosome 2 at q35 and that on chromosome 8 at q21.2 (fig 1A). RxFISH and spectral karyotyping (SKY FISH) showed this translocation clearly, but failed to show any further rearrangements ( fig lB, C). The derivative chromosomes were isolated by flow cytometry (fig ID shows the flow karyotype). Conclusions from $G$ banding were confirmed by both forward and reverse chromosome painting (not shown). The latter failed to show any deletions, suggesting a balanced reciprocal translocation. Subtelomeric fluorescent probes were used to screen telomeric regions of all chromosomes. This screen confirmed the presence of the $t(2 ; 8)$ translocation and also the presence of both $\mathrm{p}$ and $\mathrm{q}$ telomeres of the translocated chromosomes (fig IE-G). An apparent terminal deletion (absence of hybridisation signal) on Xp was observed. FISH with cosmid 34F5 (containing SHOX exons I-IV and extending distally) showed 
Table 2 Summary of BAC FISH results using clone order from August 2001 freeze of the Human Genome Browser. Clones bordering breakpoints or deleted in rearrangement are in bold type. Position on chromosome 2q: 232635159 bp-238 $902300 \mathrm{bp}$

\begin{tabular}{|c|c|c|c|c|c|}
\hline $\begin{array}{l}\text { Accession } \\
\text { No }\end{array}$ & BAC clone & $\begin{array}{l}\text { Sequence } \\
\text { Status }\end{array}$ & Size (bp) & $\begin{array}{l}\text { Known genes or } \\
\text { transcripts }\end{array}$ & FISH result \\
\hline AC009302 & RP11-71J24 & Finished & 180970 & & Not hybridised \\
\hline AC012591 & RP11-296A19 & Finished & 141950 & & Proximal \\
\hline AC010980 & RP11-38408 & Finished & 171374 & PAX3 & Proximal \\
\hline ACO12251 & RP11-16P6 & 18 fragments & 169980 & FARSLB $1^{*}$ & Chromosome 15 \\
\hline AC016843 & RP1 1-3122 & 7 fragments & 169272 & FARSLB ${ }^{*}$, AF085977 & Deleted \\
\hline AC016712 & RP11-266F17 & Finished & 159748 & & Deleted \\
\hline AC013476 & RP1 1-525G12 & 3 fragments & 194222 & FACL3 & Deleted \\
\hline AC017014 & RP11-142D10 & Finished & 182366 & & Deleted \\
\hline AC068035 & RP11-799L6 & 2 fragments & 177008 & & Not hybridised \\
\hline AC079120 & RP1 1-345M24 & 1 unordered & 181388 & & Not hybridised \\
\hline AC013448 & RP11-551D18 & Finished & 129553 & & Deleted \\
\hline ACO12512 & RP1 1-56107 & Finished & 179460 & SCG2 & Deleted \\
\hline AC016701 & RP11-183N7 & 15 fragments & 160196 & FLJ21685 fis & Deleted \\
\hline AC068343 & RP11-660K21 & 19 fragments & 190220 & FLJ21685 fis & Deleted \\
\hline AC073641 & RP1 1-368E14 & 3 fragments & 199083 & $\begin{array}{l}\text { FLJ12701 (MRLP44), } \\
\text { FLJ12826, M11783 }\end{array}$ & Not hybridised \\
\hline ACO12460 & RP11-536G14 & 9 fragments & 200885 & $\begin{array}{l}\text { FLJ12701 (MRLP44) } \\
\text { FLJ12826, M11783 }\end{array}$ & Deleted \\
\hline AC012664 & $\mathrm{RP} 11-3 \mathrm{C} 18$ & 9 fragments & 163421 & $\begin{array}{l}\text { FLJ12701 (MRLP44) } \\
\text { FLJ12826, M1 } 1783\end{array}$ & Not hybridised \\
\hline AC019109 & RP11-488C22 & 3 fragments & 184298 & & Deleted \\
\hline AC023458 & RP1 1-456121 & 24 fragments & 199134 & & Not hybridised \\
\hline AC008072 & RP1 1-408N22 & Finished & 206177 & FLJ22746 & Not hybridised \\
\hline AC079836 & RP1 1-99K 18 & 25 fragments & 153903 & FLJ22746/CUL3 & Not hybridised \\
\hline AC073052 & RP11-92F20 & 1 unordered & 152982 & CUL3 & Not hybridised \\
\hline AC092679 & RP11-676D22 & 2 fragments & 182396 & CUL3 & Not hybridised \\
\hline AC025339 & RP1 1-626D22 & 51 fragments & 185492 & CUL3 & Deleted \\
\hline ACO23985 & RP11-811014 & 29 fragments & 168684 & FLJ20220 & Not hybridised \\
\hline ACO11739 & RP11-68H19 & Finished & 171811 & FLJ20220, KIAA0694 & Not hybridised \\
\hline AC027805 & RP1 1-327P24 & 25 fragments & 145642 & KIAA0694 & Not hybridised \\
\hline ACO18382 & RP1 1-5119 & 41 fragments & 196556 & KIAA0694 & Not hybridised \\
\hline AC017095 & RP11-516C4 & 4 fragments & 185804 & KIAA0694 & Not hybridised \\
\hline AC015974 & RP1 1-467A 18 & Finished & 196544 & & Not hybridised \\
\hline AC067961 & RP1 1-59F3 & 1 unordered & 159890 & KIAA 1486 & Deleted \\
\hline ACO11035 & RP1 1-7D20 & 31 fragments & 165199 & KIAA 1486 & Deleted \\
\hline ACO19231 & RP1 1-573016 & Finished & 187268 & KIAA 1486 & Deleted \\
\hline AC016717 & RP1 1-314B1 & Finished & 210558 & KIAA1486 & Deleted \\
\hline AC068138 & RP1 1-813K12 & 7 fragments & 218165 & & Deleted \\
\hline AC069383 & RP1 1-86017 & 20 fragments & 200323 & & Deleted \\
\hline AF 107045 & N.A. & Finished & 45043 & RRM1 & Not hybridised \\
\hline AC062015 & CTD-2031E 17 & Finished & 144223 & & Not hybridised \\
\hline AC08002 & RP11-231F9 & 26 fragments & 141182 & & Not hybridised \\
\hline AC026588 & RP11-211K17 & 19 fragments & 160341 & & Distal \\
\hline AC079402 & RP11-597E15 & 10 fragments & 159078 & & Distal \\
\hline AC079769 & RP1 1-23513 & 31 fragments & 147289 & & Not hybridised \\
\hline AC010735 & RP1 1-395N3 & Finished & 211980 & IRSI & Distal \\
\hline AC073149 & RP1 1-803F15 & 44 fragments & 175504 & & Not hybridised \\
\hline AC079235 & RP1 1-495O23 & 51 fragments & 200847 & COL4A4 & Not hybridised \\
\hline
\end{tabular}

that this sequence was not deleted. PCR experiments using primer pairs located between 0 and $79 \mathrm{cR}_{10 \mathrm{k}}$ on the Stanford $\mathrm{G} 3$ radiation hybrid map within the pseudo-autosomal region of $\mathrm{Xp}$, to amplify the patient's isolated X chromosomal DNA, gave no evidence of deletion. The gastrin releasing peptide receptor gene (GRPR) was also studied by PCR and was not found to be deleted. Subsequent chromosome analysis of the phenotypically normal mother showed the same cytogenetic and molecular findings.

\section{Breakpoint mapping}

Breakpoint mapping using FISH with cytogenetically and genetically anchored CEPH YAC probes was carried out (table 1, fig 2A, B). These showed a cryptic deletion within band 2q35 at the breakpoint of the translocation chromosomes. YAC clones from proximal to the deletion hybridised to normal chromosome 2 and to der(2) while those distal to the deletion hybridised to normal chromosome 2 and to der(8). By locating markers known to be within the boundary YACs, we were able to refine measurement of this deletion using FISH with appropriate BACs (table 2, fig 2C-E). The BAC clone immediately proximal to the breakpoint was AC010980, which includes the promoter and most of the coding sequence of the paired box 3 (PAX3) gene. AC026588 was the most proximal clone derived from chromosome 2 which hybridised on $\operatorname{der}(8)$, while no hybridisation to either derivative chromosome was seen from clones between these two. These results define a deletion of 4-4.8 Mb on $2 \mathrm{q} 35$.

The breakpoint on chromosome 8 was characterised similarly by FISH with appropriate YACs (table 1) and BACs (table 3). In this case, no evidence of a deletion was found by FISH (fig 3), with clones placed proximal and distal to the 
Table 3 Summary of $8 q$ BAC FISH results using clone order derived from the August 2001 freeze of the Human Genome Browser. Clones bordering breakpoint are in bold type. Position on chromosome 8q: 103750000 bp-105050 000 bp

\begin{tabular}{|c|c|c|c|c|c|}
\hline Accession No & BAC clone & Sequence status & Size (bp) & Known genes & FISH result \\
\hline AC068510 & RP1 1-662E23 & 7 fragments & 192155 & & Proximal \\
\hline AC027258 & RP1 1-72H9 & 23 fragments & 159806 & & Proximal \\
\hline $\mathrm{AC} 023841$ & RP1 1-565L3 & 12 fragments & 161297 & & Proximal \\
\hline AC067967 & RP1 1-363H6 & Finished & 41972 & SEPP1 & Proximal \\
\hline AC017061 & RP1 1-353D5 & 8 fragments & 172403 & SLC26A7 & Distal \\
\hline $\mathrm{ACO} 27374$ & RP11-656D12 & 4 fragments & 202856 & SLC26A7 & Distal \\
\hline AC020783 & RP1 1-16M2 & 3 fragments & 156973 & & Chromosome $8 p 22$ \\
\hline AF268619 & RP1 1-122C21 & 3 fragments & 152233 & & Distal \\
\hline AC015952 & RP11-1B10 & 7 fragments & 166991 & & Chromosome $5 q 14$ \\
\hline
\end{tabular}

Table 4 Presence of STS on chromosomes of the proband as determined by PCR of isolated chromosomes. Markers bordering breakpoints or deleted in rearrangement are in bold type

\begin{tabular}{|c|c|c|c|c|c|c|}
\hline \multirow[b]{2}{*}{ Marker name } & \multicolumn{3}{|l|}{ Position (bp) } & \multirow[b]{2}{*}{ Gene† } & \multirow[b]{2}{*}{ Product size } & \multirow{2}{*}{$\begin{array}{l}\text { Amplified } \\
\text { chromosom es§ }\end{array}$} \\
\hline & Position (bp)* & $\mathrm{NCBI}$ & UCSC & & & \\
\hline \multicolumn{7}{|l|}{$2 q 35$} \\
\hline SHGC-104436 & $232636 k$ & & & PAX3 (intron) & 298 & N2, $\operatorname{der}(2)$ \\
\hline WI-7962 (D2S2599) & 232668k & & & PAX3 (cds) & 330 & N2, $\operatorname{der}(2)$ \\
\hline GDB: 603639 & 232673k & & & PAX3 (5'UT) & 278 & N2, del \\
\hline CP3PR & $232674 k$ & & & PAX3 (promoter) & 148 & N2, del \\
\hline SHGC-102627 & $232694 k$ & & & - & 343 & N2, del \\
\hline D2S313 & $232784 k$ & & & - & 149 & N2, del \\
\hline RH1 10169 & $232873 k \ddagger$ & & & - & 303 & N2, del \\
\hline stSG27208 & $233036 k$ & & & FARSLB 1 ** & 131 & N2, del \\
\hline SHGC-85602 & $236902 k$ & & & - & 308 & N2, del \\
\hline SHGC-148539 & $237059 k$ & & & - & 332 & N2, $\operatorname{der}(8)$ \\
\hline D2S2354 & $237237 k$ & & & - & $255-275$ & $\mathrm{~N} 2, \operatorname{der}(8)$ \\
\hline WI-9260 (D2S2647) & $237454 k$ & & & IRS-1 & $105-106$ & N2, $\operatorname{der}(8)$ \\
\hline \multicolumn{7}{|l|}{$8 q 21.3$} \\
\hline stSG46229 & & $89631 \mathrm{k}$ & 104070k & - & 141 & N8, $\operatorname{der}(8)$ \\
\hline WI-16423 & & $89678 k$ & 104030k & - & 129 & N8, $\operatorname{der}(8)$ \\
\hline SGC35860 & & $89771 \mathrm{k}$ & Not in UCSC database $\neq$ & LOC51633ł & 109 & N8, $\operatorname{der}(8)$ \\
\hline WI-4229 & & $90674 k$ & $101612 \mathrm{k} \ddagger$ & - & 274 & N8, $\operatorname{der}(8)$ \\
\hline SHGC-10609 & & $90018 k$ & $101402 \mathrm{k} \ddagger$ & - & 152 & N8, $\operatorname{der}(8)$ \\
\hline SHGC-155293 & & $90151 k$ & $101255 \mathrm{k} \ddagger$ & - & 283 & N8, $\operatorname{der}(8)$ \\
\hline SHGC-101603 & & $90264 k$ & $101160 \mathrm{k} \ddagger$ & MMP16 & 325 & N8, del \\
\hline SHGC-85429 & & $90377 k$ & $100045 \mathrm{k} \ddagger$ & MMP16 & 327 & N8, del \\
\hline RH110076 & & $90808 k$ & Not in UCSC database $¥$ & - & 331 & N8, $\operatorname{der}(2)$ \\
\hline D8S1476 & & $90924 k$ & $104316 k / 104628 k \pi$ & SLC26A7 $\ddagger$ & 125 & N8, $\operatorname{der}(2)$ \\
\hline SHGC-84012 & & $91187 k$ & $104735 k$ & - & 272 & N8, der(2) \\
\hline D8S1618 (WI-3120) & & $91227 k$ & $104700 k$ & - & 249 & N8, $\operatorname{der}(2)$ \\
\hline SHGC-105203 & & $91360 k$ & $104960 \mathrm{k}$ & - & 320 & N8, $\operatorname{der}(2)$ \\
\hline
\end{tabular}

*Positions on UCSC Genome Browser build 06.08.2001

†Genes assignments are from UCSC Genome Browser build 06.08.2001 except where noted.

$\ddagger$ Markers ordered or genes assigned according to NCBI contigs.

$\S N 2$ is proband's normal 2; N8 is proband's normal 8; der(2) is proband's derivative (2); der(8) is proband's derivative (8).

TAppears twice in UCSC database.

**Phenylalanyl-tRNA synthetase beta subunit: HUGO provisional designation, Dec 2001. Locus link designation PheHB.

8q21 breakpoint found adjacent on the UCSC contig (although not on that compiled by NCBI, which in the most recent build has an additional group of clones at this site).

To refine the breakpoint further, STS primer pairs were used in PCR, with the DOP-PCR amplification products of isolated (flow sorted) chromosomes of the proband as template. Results (table 4) showed complete correlation with the findings of the FISH work. The size of the deletion at the breakpoint at $2 \mathrm{q} 35$ is defined by this method as between 4.23 and 4.41 Mb. The deletion starts in AC010980 within the transcribed regions of the PAX3 gene (fig 4). STS GDB: 603639, which occurs in the $5^{\prime}$ leader sequence of the PAX3 gene, is deleted, but WI-7962, which is in exon 4 of the gene, about 5 $\mathrm{kb}$ further upstream, is present on $\operatorname{der}(2)$. AC010980 hybridises to der(2) through more than $50 \mathrm{~kb}$ of sequence which remains proximal to the breakpoint. At least 13 transcription units are completely deleted from the rear- ranged chromosome (see Discussion), but the breakpoint at the distal end of the deletion does not lie within or very close to any known gene or transcription unit.

On 8q, the breakpoint is in an area of provisional sequencing, and the contigs compiled by UCSC and NCBI are considerably different. The simplest interpretation of our results is that the marker order adopted in table 4 is correct. One marker, WI-4229, is displaced from its position in the NCBI contigs, but this displacement allows it to fit with the local order of assembly of the UCSC contigs. Otherwise, the order follows NCBI. Because of the uncertainty in contig assembly at this position, the STS amplification approach is less powerful, and the marker order may eventually prove to be different from that used in table 4. Our current evidence suggests that there is a small deletion at the $8 \mathrm{q}$ breakpoint (not detected by FISH) including part of the matrix metalloproteinasel6 

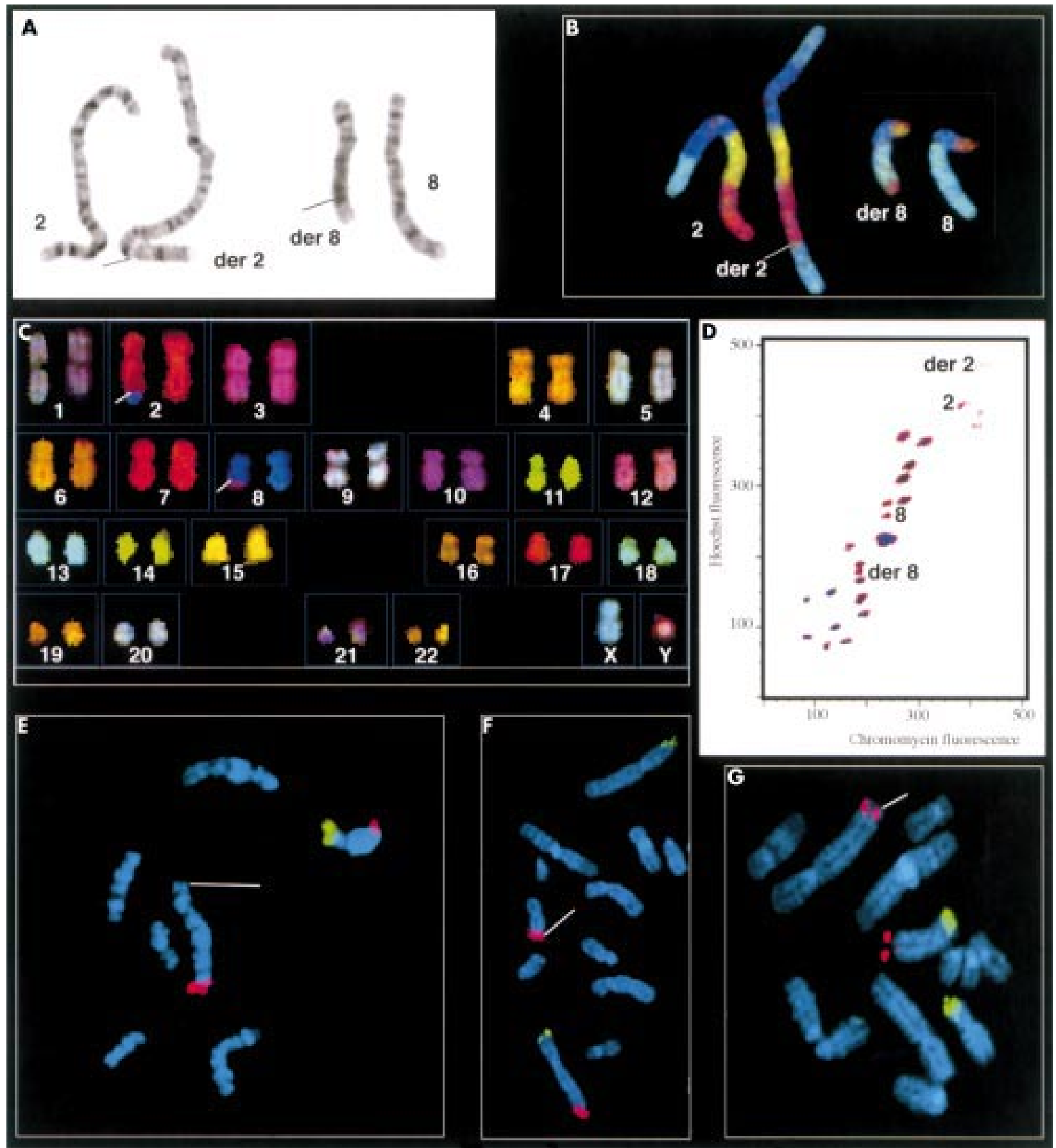

Figure 1 Initial characterisation of the proband's karyotype. (A) G banding of chromosomes 2 and 8 and derivative chromosome 2 and 8 . (B) RxFISH of chromosomes 2, 8, and derivative chromosomes 2 and 8. (C) SKY FISH of the entire karyotype. Translocation breakpoints are indicated. (D) Flow karyotype. (E-G) Subtelomeric probes do not hybridise to Xp, but show the presence of both $p$ and $q$ telomeres of chromosomes 2 and 8 . (E) $X p / Y p$ is green, $X q / Y q$ red. Note absent signal on $X p$ (arrow). (F) $2 p$ is green, $2 q$ red. Note the translocated $2 q$ signal on derivative chromosome 8. (G) 8p is green, $8 q$ red. Note the translocated 8q signal on derivative chromosome 2.

(MMP16) gene. The marker order used places this deletion at the junction with the $2 \mathrm{q} 35$ sequence.

\section{DISCUSSION}

The proband's twin sister has no developmental abnormalities, reducing the possibility that either prenatal or postnatal environmental factors are causative of autism or the other abnormalities seen in the proband. The twin sister also carries her father's balanced 5;20 translocation, verifying paternity and confirming the proband's 2;8 translocation as de novo. STS analysis of paternal and maternal DNA showed that the derivative chromosomes are paternal in origin (data not shown). Moderate ventriculomegaly as well as intrauterine growth retardation could be the direct result of decreased placental blood flow to the proband as documented during pregnancy. The proband's other abnormalities are less likely to relate to this cause and we consider these to be of genetic origin.

Chromosome breakpoint mapping using cytogenetically anchored or physically mapped YAC and BAC clones has been instrumental in detecting cryptic interstitial deletions at apparently balanced breakpoints in patients with mental 


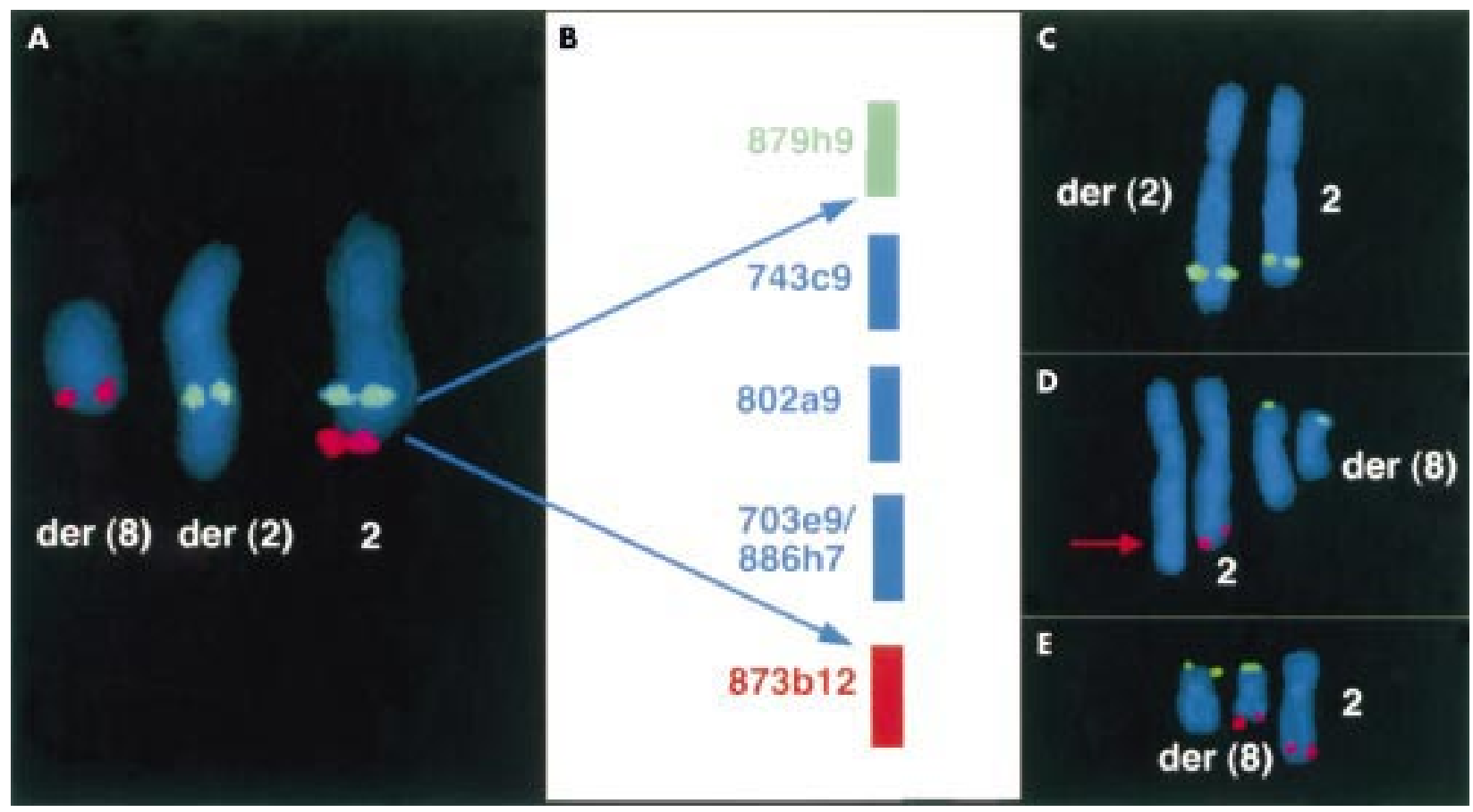

Figure 2 Characterisation of the $t(2 q ; 8 q)$ breakpoint using chromosome 2 clones. (A) FISH using YAC clones. Clone 879h9 (green) hybridises to normal chromosome 2 and $\operatorname{der}(2)$ and is proximal to the breakpoint. Clone $873 \mathrm{~b} 12$ (red) hybridises to chromosome 2 and der(8) and is therefore distal to the breakpoint. (B) Colour coded schematic representation of YAC clones; blue YACs were found to be deleted. (C-E) FISH using BAC clones. Marker 8p subtelomeric probes were cohybridised with the chromosome 2 BAC clones. (C) Clone RP1 1-384O8 hybridises proximal to the breakpoint; green signals are seen on der(2) and chromosome 2. (D) RP1 1-86017 is a representative deleted BAC clone at the region of the chromosomal deletion on der(2) (red arrow). Normal hybridisation signals (red) are seen on chromosome 2. 8p probe is green. (E) Clone $211 \mathrm{~K} 17$ is distal to the breakpoint with red hybridisation signals seen on chromosome 2 and der(8). $8 \mathrm{p}$ probe is green.
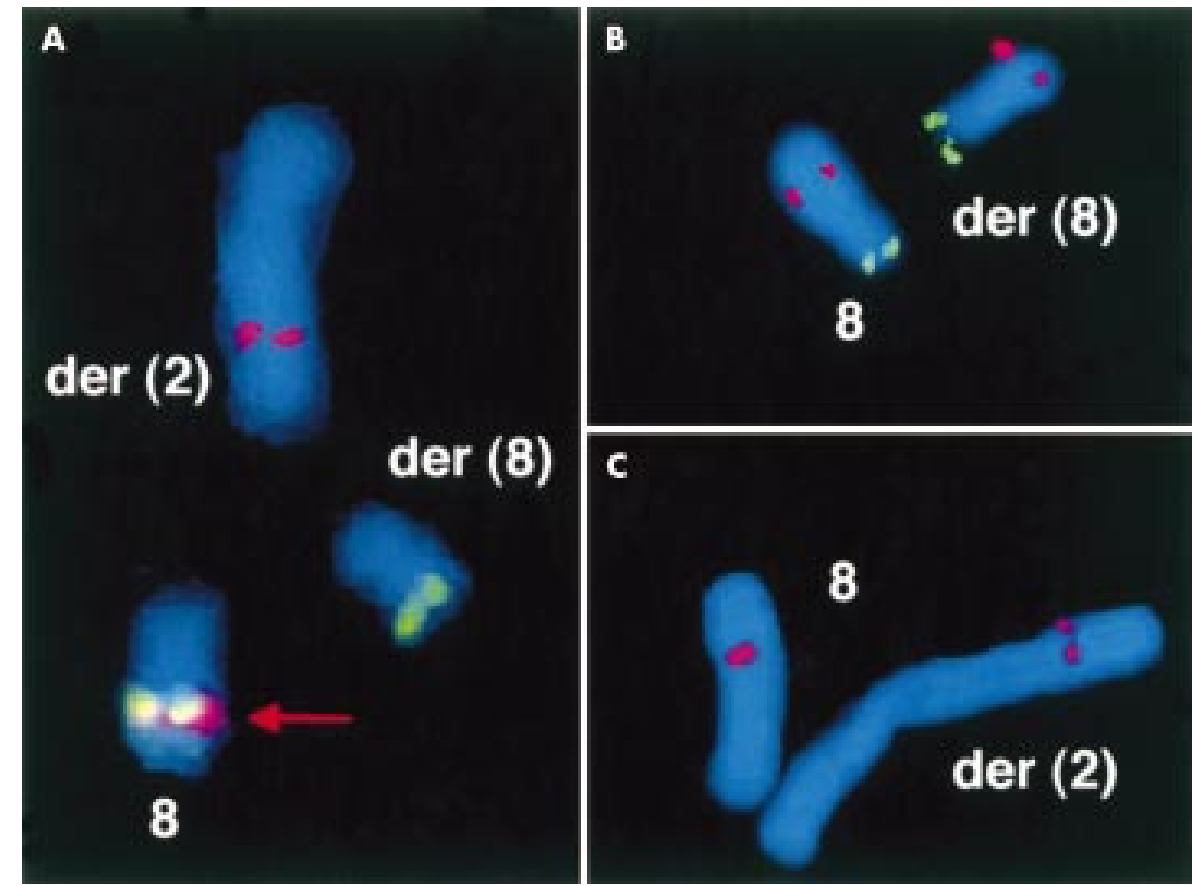

Figure 3 Characterisation of the $t(2 q ; 8 q)$ breakpoint using chromosome 8 clones. (A) FISH using YAC clones. Clones 759g8 and $725 a 6$ overlap (yellow signal/red arrow) at $102 \mathrm{cM}$ from 8p terminus. (B, C) FISH using BAC clones. (B) Clone RP1 1-662E23 is proximal and (C) clone RP1 1-353D5 is distal to the breakpoint on 8q (both red signals). An 8p telomeric probe (green) was cohybridised with clone RP1 1-662E23.

retardation, ${ }^{16}$ with about $6.5-7.4 \%$ of patients with moderate or profound mental retardation showing such deletions in two recent FISH based surveys. ${ }^{11}{ }^{19}$ Autistic children with $2 \mathrm{q}$ deletions ranging from $2 \mathrm{q} 31$ to 2qter have been reported, but where smaller deletions have been identified these have been of 2q37-2qter..$^{1112021}$ The same region has been associated with mental retardation in patients with phenocopies of Albright's syndrome. ${ }^{22}$ 


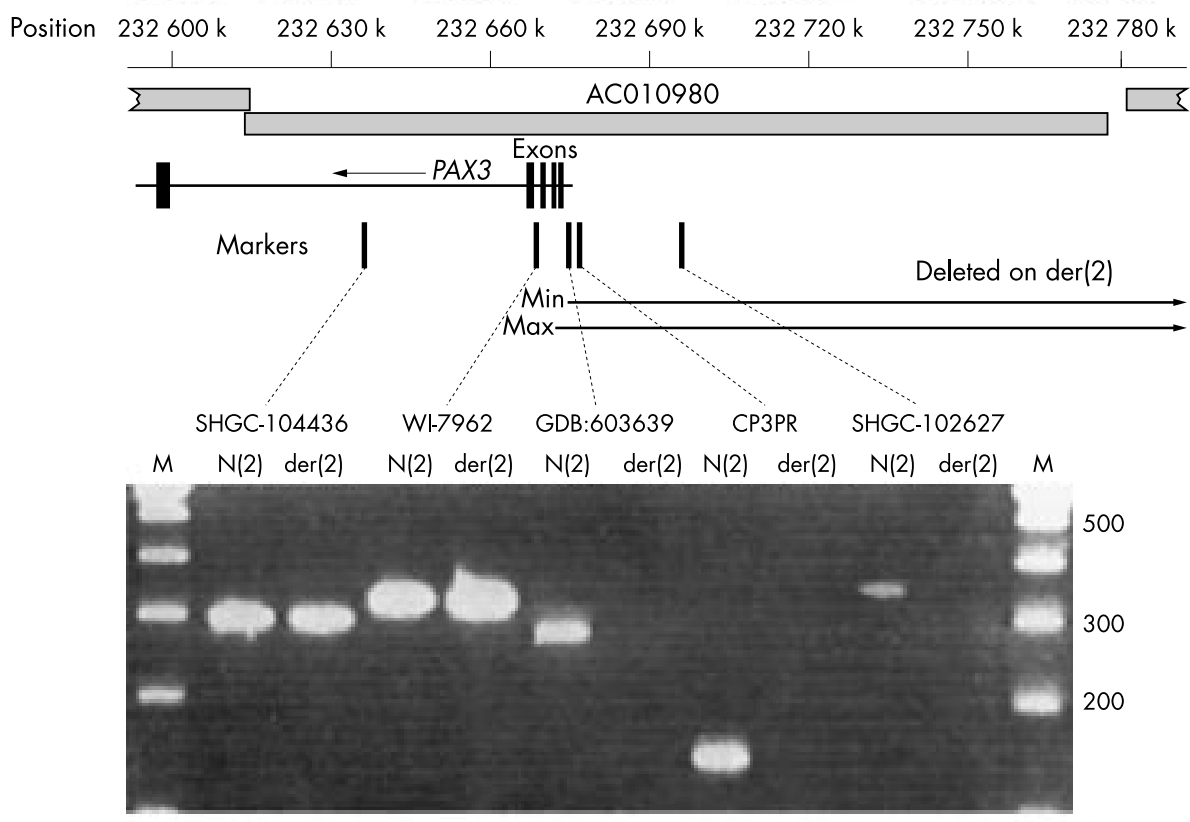

Figure 4 STS mapping of the chromosome 2 breakpoint. Amplification products of PCR using STS primers at different points along the BAC clone AC010980 are shown for normal and der(2) chromosomes. All products are of the expected sizes. There is no signal from der(2) amplifications using the last three primer pairs. (There was no signal with der(8) using any primer pair in this region, not shown.) The implied maximum and minimum end points for the deletion are shown, as well as the location of PAX3.

In our patient, both $2 \mathrm{q}$ telomeres were present, but FISH identified an apparent subtelomeric deletion of Xp. However, the use of subtelomeric probes is not by itself sufficient to identify telomeric deletions. Polymorphisms in subtelomeric probe hybridisation have recently been reported on Xp in phenotypically normal subjects, as have reductions in repeat length and signal strength on $2 q^{23}$ The absence of signal from Xp subtelomeric probe on one maternal X chromosome as well as in the proband and the lack of a measurable associated deletion make it likely that the phenotype of the patient is not associated with Xp polymorphism. Instead, we hypothesise that the phenotype is the result of genetic damage associated with the 2;8 translocation. This includes deletion of genetic material at $2 \mathrm{q} 35$, potentially together with genetic damage on 8 and/or production of a fusion gene and position effects on gene expression arising from the translocation.

In the UCSC golden path, the $2 \mathrm{q} 35$ deletion completely removes five genes of known function. These are phenylalanine tRNA synthetase-like, beta subunit, (referred to as $P h e H B$ in genome databases and provisionally named FARSLBI by HUGO, Dec 2001), fatty acid coenzyme A ligase long chain 3 (FACL3), secretogranin II (SCG2), cullin 3 (CUL3), and ribonucleotide reductase $\mathrm{Ml}$ polypeptide $(R R M 1)$. In the equivalent ensEMBL and NCBI contigs, RRMI does not appear and it appears to be misplaced judging by somatic cell mapping studies and in situ hybridisation. ${ }^{24}$ In addition, there are nine transcription units of unknown function in the deleted region (table 2). None of these 13 genes has been associated with any inherited disorder, but the first four are all expressed in brain, while secretogranin II is a constituent of secretory vesicles which has only been found in brain tissues.

Two known and two hypothetical genes have been mapped close to the 8q21.3 breakpoint. The known genes are selenoprotein P plasma 1 (SEPP1) and matrix metalloproteinase 16 (MMP16). SEPPI appears on the breakpoint proximal BAC on the UCSC $8 \mathrm{q} 21.3$ contig, but also on chromosome $5 \mathrm{q} 31$ in the same database (that is, it is assigned two positions), while the 5 q31 position agrees both with the chromosome assignment on the NCBI databases and with the comparative mouse mapping data. (The gene is not assigned on ensEMBL.) The gene encod- ing MMP16 protein, a membrane bound or secreted matrix metalloproteinase, is close to the breakpoint on the NCBI databases, but assigned a more proximal position on UCSC. Our STS data show disruption of MMP16 on der(8). Deletion or damage to $M M P 16$ at the $8 \mathrm{q}$ breakpoint may be significant in the phenotype. MMP16 mRNA is expressed at high levels in brain, as well as in other tissues, and is likely to function in processes such as development and tissue remodelling. Currently no diseases have been connected with mutation in this gene, and there are no reports of autism or mental retardation syndromes mapping in the immediate region of the $8 \mathrm{q}$ breakpoint. A well characterised $(\mathrm{X} ; 8)(\mathrm{p} 22.3 ; \mathrm{q} 22.1)$ translocation in a patient with autism and multiple exostoses has a breakpoint on chromosome 8 , which is $30 \mathrm{~kb}$ distal to the syndecan 2 (SDC2) gene. ${ }^{25}$ This is some $5 \mathrm{Mb}$ distal to the breakpoint in the present patient. (The GRPR gene, which lies across the breakpoint on $\mathrm{Xp}$ in that patient, appears to be intact in our patient although we cannot rule out point mutations.) The present breakpoint also lies distal to the mapped Nijmegen breakage syndrome gene (NBS1) in the current genome map and is proximal to the Cohen syndrome defined region. ${ }^{26}$

Haploinsufficiency of $P A X 3$ has been shown to be causative of many cases of Waardenburg syndrome (WS). ${ }^{27}$ WS is an autosomal dominant disorder that manifests as a complex of sensorineural deafness, pigmentation defects (characteristically a white forelock and heterochromia irides, but can include hypopigmented patches of skin and retinal fundus), and minor but characteristic facial abnormalities including dystopia canthorum. In a few WS patients, endolymphatic hydrops (raised pressure in endolymphatic spaces of cochlea and vestibular system caused by aplasia of the posterior semicircular canal) is associated with painful hyperacusis or tinnitus. Occasionally, Waardenburg syndrome has been observed combined with mental retardation. A case of mental retardation and WS with upper limb contractures (KleinWaardenburg syndrome or WS type 3) was described in a patient with a deletion of $2 \mathrm{q} 35-\mathrm{q} 36 .{ }^{28}$ Most signs of WS may be more or less evident depending on the genetic background of the patient. ${ }^{29}$ However, dystopia canthorum is characteristic of patients with WS1 and WS3, in all of whom PAX3 mutation is considered to be responsible for the condition. 
The 2q35 deletion mapped in this study spans the entire promoter and the leader sequence of $P A X 3$ so that it is very unlikely that functional PAX3 mRNA will be produced from $\operatorname{der}(2) \cdot{ }^{30}$ The possibility that a fusion protein (MMP16-PAX3) could be produced at the breakpoint is under investigation. The proband shows mild dystopia canthorum, and his sensitivity to high pitched sounds may be a result of endolymphatic hydrops, but he has no pigmentary anomalies of the hair, iris, skin, or retinal fundus. His other abnormalities have not previously been associated with WS.

Four international or large linkage studies have associated autism with regions on chromosome $2 \mathrm{q},{ }^{6-9}$ but these are slightly centromeric to our cryptic deletion, and probably too far away for the same genes to be involved as those deleted in our patient. ${ }^{31}$ Two other studies have not reported linkage of autism to $2 q^{32}{ }^{33}$ The observed cryptic deletion may be responsible for the patient's phenotype, so that a gene (or genes) responsible for autism maps to a $4.3 \mathrm{Mb}$ region of $2 \mathrm{q} 35$. In this case, it is likely that the phenotype is associated with haploinsufficiency, although we are examining genes on the patient's normal $2 \mathrm{q} 35$ for point mutation. MMP16 on $8 \mathrm{q} 21.2$ and the region of $2 \mathrm{q} 35$ at, or immediately distal to, the $P A X 3$ gene should be considered when assessing the genetic background of autistic patients, especially those with developmental delay but no (or only subtle), dysmorphic features.

\section{ACKNOWLEDGEMENTS}

We would like to thank P Viertel and D Vogt for preparation of YAC probes, W Rens for 24 colour paint pools, D J Shears for SHOX gene probe and clones, M T Ross for Xp cosmid clones and Xp-STS primer pairs, and J Smith for secretarial assistance. We are also grateful to the family for their collaboration in this study. This work was supported by a scholarship from the Association of Commonwealth Universities and a grant from the EU-Commission (BMM4-CT97-2268) to IB and a grant from the German Genome Programme (grant No 01KW99087) to HHR. The Wilhelm Johannsen Centre for Functional Genome Research was established by the Danish National Research Foundation.

Electronic database information. University of California Santa Cruz Human Genome Browser, August 062001 freeze (UCSC golden path): http://genome.cse.ucsc.edu/goldenPath/aug200lTracks.html. NIH National Centre for Biotechnology Information, Entrez genome view, build 26, (NCBI contigs): http://www.ncbi.nlm.nih.gov/cgi-bin/ Entrez/map search. European Molecular Biology Organisation Genome Server, August freeze (EnsEMBL): http://www.ensembl.org/

\section{Authors' affiliations}

I Borg, M Squire, P C M O'Brien, M A Ferguson-Smith, D R Sargan, Centre for Veterinary and Biomedical Science, University of Cambridge, Cambridge, UK

I Borg, C Menzel, K Stout, H H Ropers, V M Kalscheuer, Max Planck Institute for Molecular Genetics, Berlin, Germany

D Morgan, L Willatt, Clinical Cytogenetics Laboratory, Addenbrooke's NHS Trust, Cambridge, UK

I Borg, Department of Medical Genetics, Addenbrooke's NHS Trust, Cambridge, UK

N Tommerup, Wilhelm Johannsen Centre for Functional Genome Research, Department of Medical Genetics, IMBG, University of Copenhagen, Denmark

\section{REFERENCES}

1 Fombonne E. The epidemiology of autism: a review. Psychol Med 1999;29:769-86.

2 Smalley SL, Asarnow RF, Spence MA. Autism and genetics. A decade of research. Arch Gen Psychiatry 1998;45:953-61.

3 Bailey A, Le Couteur A, Gottesman I, Boldton P, Simonoff E, Yuzda E, Rutter M. Autism as a strongly genetic disorder: evidence from a British twin study. Psychol Med 1995;25:63-77.

4 Steffenburg S. Neuropsychiatric assessment of children with autism: a population based study. Dev Med Child Neurol 1991;33:495-511.

5 Gillberg C. Chromosomal disorders and autism. J Autism Dev Disord 1998;28:415-25

6 The International Molecular Genetic Study of Autism Consortium. A full genome screen for autism with evidence for linkage to a region on chromosome 7q. Hum Mol Genet 1998;7:571-8.
7 The International Molecular Genetic Study of Autism Consortium A genome-wide screen for autism: strong evidence for linkage to chromosomes 2q, 7q and 16p. Am J Hum Genet 2001;69:570-81.

8 Philippe A, Martinez M, Guilloud-Bataille M, Gillberg C, Rastam M Sponheim E, Coleman M, Zapella M, Aschaver H, Van Maldergem L, Penet C, Feingold J, Brice A, Leboyer M. Genome-wide scan for autism susceptibility genes. Paris Research International Sibpair Study. Hum Mol Genet 1999;8:805-12.

9 Buxbaum JD, Silverman J M, Smith CJ, Kilifarski M, Reichert J, Hollander E, Lawlor, BA, Fitzgerald M, Greenberg DA, Davis KL. Evidence for a susceptibility gene for autism on chromosome 2 and for genetic heterogeneity. Am J Hum Genet 2001;68:1514-20.

10 Ghaziuddin M, Burmeister M. Deletion of chromosome 2 q37 and autism: a distinct subtype? J Autism Dev Disord 1999;29:259-63.

11 Conrad B, Dewald G, Christensen E, Lopez M, Higgins J, Pierpont ME. Clinical phenotype associated with terminal 2q37 deletion. Clin Genet 1995:48:134-9.

12 Mendelian Cytogenetics Network. Systematic identification of disease genes by structural chromosome rearrangements. EU-Concerted Action (Biomed 2). BMH4-CT97-2268. (http://mcndb.imbg.ku.dk).

13 Telenius H, Carter NP, Bebb CE, Nordenskjold M, Ponder BA Tunnacliffe A. Degenerate oligonucleotide-primed PCR: general amplification of target DNA by a single degenerate primer. Genomics 1992;13:718-25

14 Carter NP, Ferguson-Smith MA, Perryman MT, Telenius $\mathrm{H}$, Pelmear $\mathrm{AH}$, Leversha MA, Glancy MT, Wood SL, Cook K, Dyson HM. Reverse chromosome painting: a method for the rapid analysis of aberrant chromosomes in clinical cytogenetics. J Med Genet 1992;29:299-307

15 Muller S, O'Brien PC M, Ferguson-Smith MA, Weinberg J. Cross-species colour segmenting: a novel tool in human karyotype analysis. Cytometry 1998;33:445-52.

16 Wirth J, Northwang HG, van der Maarel S, Menzel C, Borck G, Lopez-Pajares I, Brondum-Nielsen K, Tommerup N, Bugge M, Ropers HH, Haaf T. Systematic characterisation of DBCRs by FISH: cytogenetically and genetically anchored YACs identify microdeletions and candidate genes for mental retardation genes. J Med Genet 1999:36:271-8.

17 Sargan DR, Yang F, Squire M, Milne BS, O'Brien PCM, Ferguson-Smith MA. Use of flow-sorted canine chromosomes in the assignment of canine linkage, radiation hybrid, and syntenic groups to chromosomes: refinement and verification of the comparative chromosome map for dog and human. Genomics 2000;69:182-95

18 Rossi E, Piccini F, Zollino M, Neri G, Caselli D, Tenconi R, Castellan C, Carrozzo R, Danesino C, Zuffardi O, Ragusa A, Castiglia L, Galesi O, Greco D, Romano C, Pierluigi M, Perfume C, Di Rocco M, Faravelli F, Dagna Bricarelli F, Bonaglia M, Bedeschi M, Borgatti R. Cryptic telomeric rearrangements in subjects with mental retardation associated with dysmorphism and congenital malformations. J Med Genet 2001;38:417-20

19 Knight SJL, Regan R, Nicod A, Horsley SW, Kearney L, Homfray T, Winter RM, Bolton P, Flint J. Subtle chromosomal rearrangements in children with unexplained mental retardation. Lance 1999:354:1676-81

20 Smith M, Escamilla JR, Filipek P, Bocian ME, Modahl C, Flodman P, Spence MA. Molecular genetic delineation of $2 q 37.3$ deletion in autism and osteodystrophy: report of a case and of new markers for deletion screening by PCR. Cytogenet Cell Genet 2001;94:15-22

21 Burd L, Martsolf JT, Kerbeshian J, Jalal SM. Partial 6p trisomy associated with infantile autism. Clin Genet 1988:33:356-9.

22 Wilson LC, Leverton K, Oude Luttikhuis MEM, Oley CA, Flint J, Wolstenholme J, Duckett DP, Barrow MA, Leonard JV, Read AP, Trembath RC. Brachydactyly and mental retardation: an Albrigh hereditary osteodystrophy-like syndrome localised to 2q37. Am J Hum Genet 1995;56:400-7

23 Knight SJL, Flint J. Perfect endings: a review of subtelomeric probes and their use in clinical diagnosis. J Med Genet 2000;37:401-9.

24 Brissenden JE, Caras I, Thelander L, Francke U. The structural gene for the $M 1$ subunit of human ribonucleotide reductase maps to chromosome 11 , band p15, in human and to chromosome 7 in mouse. Exp Cell Res 1988; 174:302-8.

25 Ishikawa-Brush Y, Powell JF, Bolton P, Miller AP, Francis F, Willard HF, Lehrach $\mathrm{H}$, Monaco AP. Autism and multiple exostoses associated with an X;8 translocation occurring within the GRPR gene and 3' to the SDC2 gene. Hum Mol Genet 1997;6:1241-50.

26 Kolehmainen J, Norio R, Kivitie-Kallio S, Tahvanainen E, de la Chapelle A, Lehesjoki AE. Refined mapping of the Cohen syndrome gene by linkage disequilibrium. Eur J Hum Genet 1997;5:206-13.

27 Tassabehii M, Read AP, Newton VE, Harris R, Balling R, Gruss P Strachan T. Waardenburg's syndrome patients have mutations in the human homologue of the Pax-3 paired box gene. Nature 1992;355:635-6.

28 Pasteris NG, Trask BJ, Sheldon S, Gorski JL. Discordant phenotype of two overlapping deletions involving the PAX3 gene in chromosome 2q35. Hum Mol Genet 1993;2:953-9.

29 DeStefano AL, Cupples LA, Arnos KS, Asher JH Jr, Baldwin CT, Blanton S, Carey ML, da Silva EO, Friedman TB, Greenberg J, Lalwani AK, Milunsky A, Nance WE, Pandya A, Ramesar RS, Read AP, Tassabejhi M, Wilcox ER, Farrer LA. Correlation between Waardenburg syndrome phenotype and genotype in a population of individuals with identified PAX3 mutations. Hum Genet 1998; 102:499-506.

30 Okladnova O, Syagailo YV, Tranitz M, Riederer P, Stober G, Mossner $R$, Lesch KP. Functional characterization of the human PAX3 gene regulatory region. Genomics 1999;57:1 10-19. 
31 Lamb JA Moore J, Bailey A, Monaco AP. Autism: recent molecular genetic advances. Hum Mol Genet 2000;9:861-8.

32 Barrett S, Beck JC, Bernier R, Bisson E, Braun TA, Casavant TL, Childress D, Folstein SE, Garcia M, Gardiner MB, Gilman S, Haines JL, Hopkins K, Landa R, Meyer NH, Mullane JA, Nishimura DY, Palmer P, Piven J, Purdy J, Santangelo SL, Searby C, Sheffield V, Singleton J, Slager S, Struchen T, Svenson S, Vieland V, Wang K, Winklosky B. An autosomal genomic screen for autism. Collaborative linkage study of autism. Am J Med Genet 1999;88:609-15
33 Risch N, Spiker D, Lotspeich L, Nouri N, Hindis D, Hallmayer J, Kalaydjieva L, McCague P, Dimiceli S, Pitts T, Nguyen L, Yang J, Harper C, Thorpe D, Vermeer S, Young H, Hebert J, Lin A, Ferguson J, Chiotti C Wiese-Slater S, Rogers T, Salmon B, Nicholas P, Petersen PB, Pingree C MacMahon W, Wong DL, Cavalli-Sforza LL, Kraemer HC, Myers RM. A genomic screen of autism: evidence for a multilocus etiology. Am J Hum Genet 1999;65:493-507.

\section{New mutations in hereditary pancreatitis}

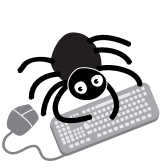

Please visit the Journal of

Medical

Genetics

website [www.

jmedgenet.com]

for link to this

full article.
Wo new mutations in gene PRSS1, which causes hereditary pancreatitis, have been reported. This autosomal dominant condition, associated with recurring bouts of acute pancreatitis, developing chronic pancreatitis, and a high incidence of pancreatic cancer, is usually caused by mutations $\mathrm{R} 122 \mathrm{H}$ and N29I in the cationic trypsinogen PRSSI gene.

By sequencing the gene in the index case in families without these mutations with sequential AflIII restriction endonuclease digestion (of exon 3, then exon 2, then exon 1,3,4,5 if any of the preceding exons were negative) and new codon 29 RFLP analysis with Bst4CI, Pfützer et al discovered a mutation resulting in an amino acid substitution R122C in one family and an amino acid substitution N29T in another, unrelated, family. Each mutation showed autosomal dominant segregation within the family.

Neither new mutation was found in 58 patients with hereditary pancreatitis who did not have $R 122 \mathrm{H}$ or N29I mutation, 66 patients with familial or idiopathic pancreatitis, or 130 healthy controls.

AflIII digestion did not detect R122C mutation, Bst4CI digestion did detect N29T mutation, so non-standard techniques are needed to identify these new mutations.

\ Gut 2002;50:271-273. 